\section{Identity and Addiction: A Psychosocial Clinical Consideration}

\author{
Vazquez ASR * and Garcia LRC \\ Regional Delegation State of Mexico Oriente, Head of Medical Services, \\ Coordination of Planning and Institutional Liaison, Medical Assistant Coordina- \\ tion of Health Research, Mexican Social Security Institute, Mexico
}

\begin{abstract}
The role of the other gives importance to understand the notion of addiction in the cultural and collective order that precipitates that the addiction itself has different edges and also urgent to be raised so that the understanding in the order of symptom is present, enable the devices of the Articulated addiction in the subjectivity of the subject multiplies the means to treat addictions. The problem of identity in the subject is given by aspects of placidity, a conflict is manifested in which for the subject it is necessary to know where it belongs or who it is, in the identity process the product of identification is numbered the possibility To make addiction is built to constitute the subject as the subject of himself. In this sense, the addict is a slave to himself effect addiction. Choosing a certain addiction seems to drag the problem that the subject is suffering from, that is, the addiction is the door to the backyard of the vestige, it is the effect of an underlying problem destabilized and at the high point of such evil /being, the addiction is It becomes a substitute for what the subject has lost from identification.
\end{abstract}

Keywords: Addiction; Clinic; Identity; Identification; Social relations

\section{Introduction}

Raising aspects related to addictions always invites us to reflect on the historical processes, the social relations of the subject that is considered addicted. The spaces where subjectivities are created that are organized and managed. The sentence was given to the addicted person from the point of view of progress, from the dialectic of

*Corresponding author: Vazquez ASR, Regional Delegation State of Mexico Oriente, Head of Medical Services, Coordination of Planning and Institutional Liaison, Medical Assistant Coordination of Health Research, Mexico, Tel: +52 5581761458; Email: alanraposocarax@gmail.com

Citation: Vazquez ASR, Garcia LRC (2019) Identity and Addiction: A Psychosocial Clinical Consideration. J Alcohol Drug Depend Subst Abus 5: 014.

Received: December 06, 2019; Accepted: December 20, 2019; Published: December 27, 2019

Copyright: () 2019 Vazquez ASR, et al. This is an open-access article distributed under the terms of the Creative Commons Attribution License, which permits unrestricted use, distribution, and reproduction in any medium, provided the original author and source are credited. "the good - the bad" is gestated in the disappearance, in the extermination. The treatment of an addicted person is similar to the Nazis with the [1] says "Modern life revolves around work and consumption, two stages of the same process based on the 'needs' never met. In this sense, we are immersed, so to speak, in a culture of addiction". The addict is undoubtedly within the regime of society, within the symbolic prison that reproduces the social. The imperative of thinking of the addict as an axis lies in the possibility of making it a symptom.

One of the statutes in which the concept of addiction has been problematized is that which [2] grants by saying that "Addiction, to drugs or alcohol (addiction, drug or alcohol) Repeated consumption of one or more psychoactive substances, up to the point that the consumer (called an addict) is periodically or continuously intoxicated, shows a compulsive desire to consume the preferred substance (or substances), has an enormous difficulty in voluntarily interrupting or modifying the consumption of the substance and shows determined to obtain psychoactive substances by any means. Usually, there is a marked tolerance and a withdrawal syndrome that occurs frequently when consumption is interrupted. The life of the addict is dominated by the consumption of the substance until it comes to exclude virtually all other activities and responsibilities. The term addiction also implies that the consumption of the substance has a detrimental effect on society and on the person; referred to alcohol consumption, it is equivalent to alcoholism. "Addiction" is an old term and variable use. It is considered by many experts as a disease with its own entity, a debilitating disorder rooted in the pharmacological effects of the substance, which follows a relentless progression. Between the 1920 s and 1960s, several attempts were made to differentiate between "addiction" and "habituation", a less severe form of psychological adaptation. In the decade of the 60s the World Health Organization recommended that both terms be stopped in favor of dependency, which can have several degrees of severity. The definition serves as a procedure and as an object to refer to a failure, without However, the interventions highlight that the link between addictions and society exists in a plausible and evident way when it is submitted to the analysis. The problematization of the status of addiction is subject to the articulation of social and clinical fields.

The role of the other gives importance to understand the notion of addiction in the cultural and collective order that precipitates that the addiction itself has different edges and also urgent to be raised so that the understanding in the order of symptom is present, enable the devices of the Articulated addiction in the subjectivity of the subject multiplies the means to treat addictions. Research and clinical matters should not lose the specificity of what surrounds the addict. The topics that addiction represents a focus on health without making the social sciences factor obsolete or null.

"At present, where health is the full right of the people and prioritized responsibility of the State, the struggle to raise the physical, psychological, social and spiritual well-being of citizens does not culminate with reaching outstanding life expectancy figures, reducing maternal mortality -infantile, control the main parasitic conditions, 
systematically complete a broad-spectrum immunization program, and raise the level of information and education on issues related to the important health-disease dialectic pair. In our country, these objectives have been achieved' [3]. Thus the importance of the approach to addicts takes another direction, given that it contemplates aspects that are parallel to medical treatment. Deconstructing addiction is not a simple task since it involves taking into account elements that are constantly mutating, the failure of the purely biological and medical structure focuses on attention for the same attention, [4] ensures that "In order for addiction to develop, chronic exposure to the substance is required and involves complex interactions between biological and environmental factors, which could explain why some individuals become addicted and others do not, as well as the failure of purely biological or purely environmental models when trying to understand these disorders", the insistence on defining elements of addiction is immersed in the universality or generality of providing immediate responses to such a complex phenomenon even when diversity allows enriching the phenomenon.

Addiction is a direct sense is necessary to think about it in terms of identity since an operational definition would support that there are parameters where an addict can be measured in his discomfort condition, the symptoms that reflect the addicted subject are causalities of a framework of the same society as coercive and punishing. The addict is not subject to a response from a failed system, it is a symptom that something happens. Now, to think of this subject as alien to society is to segment it, however, in terms of group, there is always an identification process by which the statutes of a certain conglomerate of people identified with an end are accessed, with the established norms, with the satisfactions that this group weighs, as such the group with which a subject is identified, in this case, the addict. The addiction is therefore surprising to be one more group of belonging, unlike "positive" groups the addict "clings to addictive behavior as a means of avoiding the internal experience of abandonment" hence it is possible to think in conditions of negativity.

The perspective of addiction based on what the "drug" object returns to the subject is presented as an identification record in which the addict will perpetually try to consolidate said identification, the effect of the drug only works as a tampon of certain intentionality identification, what the addicted subject enjoys is not the drug itself but what flows from it, assures that "This is why the drug addict would consume to dive into a state of ideal support that recreates the complacent image in The here and now. Also as in the Freudian model under the state of drunkenness by the drug the subject manages to dominate the repression, allowing the expression of his enjoyment". The identifying recreations that the drug addict seeks are problematic with the ligature of the social since the nullity of the act by the law is always present. The cut that society makes to the addict takes effect when the addict is understood and finds the causal identification of the act, that is, the support of the effect.

The identification is a contradiction in itself since it is pointed out that the identity crisis jumps in adolescence, a stage in which the largest population of drug addicts is statistically focused, in the Report on the situation of drug use the [5] notes that "Substance use is higher in men than in women, however, the gap in the prevalence of consumption is decreasing, especially in the adolescent population. In the case of this age group, substance use in women equals consumption in men and even exceeds it in some substances, such as amphetamine-type stimulants. Therefore, it is necessary to continue strengthening the implementation of prevention and treatment strategies with a gender perspective and aimed at the young population. Drug use in specific populations, such as adolescents in treatment centers for infringing criminal laws, suggests the need to develop programs and strategies that focus their actions on variables that violate the ability to cope with risk. of consumption, which must be intervention programs other than those used with the general population, statements that frame the population where drug use is mostly focused.

\section{Developing}

The derivation of this aspect (which not only focuses on adolescence, but it is possible to raise it from there) dates from the identity conflict that arises in that period, since there is a significant rupture with a childish I before which the sinking and the suffering for that break collide in these acts as well as the painful passage through an adult I that will be more aggressive and inquisitive, this cut represents an intense burden on the family and school factor, where they must attend the pit, the temporary fissure in a subject It expands into your adulthood when there are no media where this identity crisis takes effect. Therefore, as would say, "the personality of the drug addict is lodged in the structure diagnosed as perverse. The constant transgression of the Law both familiar and the rest of the world, makes us suppose that the drug addict refuses to accept the "non-perpetuated fusion" full and without limits with everything that represents the mother figure, that is, that does not accept castration, cutting, the prohibitions of the father.

The problem of identity in the subject is given by aspects of placidity, a conflict manifests in which for the subject it is necessary to know where he belongs or who he is, where he is, in the identity process the product of identification. The possibility of making addiction is built to constitute the subject as the subject of himself. In this sense, the addict is a slave to himself effect addiction. There is a condition of identification that is reflected in another, [6] comments that "the identification aspires to conform to the self, similar to the other taken as a model", a sense that rests on addiction. The identification that gives rise to the identity of the addict is placed in their comfort. To think of addiction as a medical aspect is necessary to do it from the understanding of this process since the addict is in the conflict of being, the positions of eradication of the addicted behavior will return in other ways, it does not necessarily imply a negative or decomposed behavior, the subject orders its reality from this effect, from this identification, so when referring to the issue of the identity of the addict is to enable it to a new aspect of analysis for their attention and possible eradication.

Integrate social processes as unfailing and buildable of social subject's medicine must deal with these intersubjective sets that from the process of the subject itself is responsible for their health. The foundation of this assertion focuses on the approach that the constitution of the so-called historical-social subject, in the end, a political subject records the advent of thinking about the path of health by determining the condition of dispensing with the social in its breadth. The subject's addiction is the effect of a social process, that is to say, thinking about medical possibilities of intervention for the addict is ineffective anesthesia since the real problem that comes from the fruit of the other social is not centered. The character of addiction as a symptom of the subject is a symptom of society itself; this social issue is presented as a cardinal necessary to think health urgently in participation and 
action from social thought. The building of addiction is centered in this case on the basis of the identity of the subject, an identity that is restricted and co-opted by an order of history, society and the manifestation of processes in the subject's body. The configuration of addiction in relation to identity as something indissoluble that leads to the subject's own conflict, identity makes the loop to determine the "animal" makes it subject, such contradiction is also reflected in the act of drug addiction. that as it has been raised is a specific demand to society itself. The manifest interest of the drug addict is pointed out as a problem to be silenced; the medical effects that protect the health of the addict forget and somehow "place" the said concern of the addict.

In this sense, addiction is presented as the enemy to overcome; the medical discourse clears the peripeteia of thinking - like this essay the addiction linked to an identity process that represents for the subject, on the one hand, the way in which symptoms are made. Failures of the social and well the link where the addict himself is linked to social reality. "As is well known, over the last few years there have been a series of important changes regarding the social consideration of drug addicts so that they are considered less as vicious and delinquent and more as sick, which by force it also entails an important change in the form of intervention: repressive measures are no longer advocated, but assistance, therapeutic" [7]. Addiction is a way of reflecting the roots of what is problematized in the subjectivity of the addict, medicine makes efforts to understand the process of organic change in the body, although involvement as a health problem goes beyond the process of prohibition or Well of rehabilitation, understanding addiction from a broader point of view is posed as an urgency to reveal. The rule of medicine is to address the emergence of the discomfort of addiction from the organic position, appealing to medication as a response implies the invalidity of the history of the subject addicted patient. The order of the addict's famine has therefore a notion of an identifying symptom; the identity of the addict is presented as an inscription of his own doing. The deployment of addiction thought as an effect of identity implies the possibility of reversing the same addiction. Addiction is a response to the story itself and is articulated in the subject as a holy possibility that can build beliefs.

It is peremptory, addiction and identity are directly registered as the meeting point of the subject with the social, the embracing of the addiction scheme is the fall of the mystification of addiction as an alien, and this symptom is glimpsed to the realism that of the social affects. The addicted subject identifies with the drug is its imperative to make a difference and call of the social symptom in response to its context. Legitimizing addiction as a disease ailment has been worked eagerly for its eradication, but there is a necessary aspect in the difference that qualifies the possibility of seeing the subject's addiction from identification, a relationship that can be thought of as a call to attend, undoubtedly this summons to attend from its breadth, by ensures that "the concept of personal identity is at the center of addictive phenomena. Specifically, people belonging to groups without a clear identity (for example, socially marginalized minorities) or so having that identity have lost it or are very deteriorated, as a result of a series of frustrations and particularly stressful life events (adolescence, school failure and dropping out of school, death of a particularly dear person, divorce, loss of a job that he believed for life, etc.) will try ardently to seek a new positive personal identity. But since we extract our identity from our group and social identity, people in that situation will look for that identity they need in groups that support them socially so that they run the risk of falling into the hands of religious, political or other sects, or in groups that, giving them social support, also require a series of dangerous behaviors (alcohol or tobacco use, illegal drugs, etc.).

Choosing a certain addiction seems to drag the problem that the subject is suffering from, that is, the addiction is the door to the backyard of the vestige, it is the effect of an underlying problem destabilized and at the high point of such evil / being, the addiction is It becomes a substitute for what the subject has lost from identification, and only through such a position in the addicted subject is identification presented as the salvation of an illusion, the salvation of recovering what he lost on the road before re Meaning your identity. Remaining in addiction makes the subject a degraded identity that forges a double effect, on the one hand the addict is subject to punitive accusations and on the other the society resents the addict. The development of addiction focuses on the question of "speaking" as a clinic, the saying of the addicted subject refers to the failed responsibility of the social and the clinic would propose re-numbered what has been lost, to make it homeostatic effect and for society [8] states that "Already given as a healing, training or probing agent, psychoanalysis has only one medium: the patient's word. The evidence of the fact does not excuse being neglected. Now, every word calls for an answer. We will show that there is no word without an answer, even if he finds nothing but silence, as long as he has a listener, and that this is the crux of his function in the analysis. But if the psychoanalyst ignores that this happens in the function of the word, he will only experience his call more strongly, and if it is the void that is first made to be heard, it is in himself where he will experience it and will be beyond the word where he will look for a reality that fills that void".

It is possible to think of addiction as how the subject links his symptom with the other harmoniously and dangerously, places the nullity of knowledge, addiction is the bunker that covers the anxiety of knowing, it is also a direct denial to itself same, a way of disintegrating, the addicted subject is disappeared from himself, it is another that expresses the drug, the exposed subject is a matter of security to not give an account of the unconscious subject, a subject that needs to have a word to be. The intentionality of the clinic arising from speech is the active step to act on the social order. The clinic understood from the psychoanalysis would allow an effective mode of functionality that would produce the understanding of the identity of the addict to account for the historical cut that takes place in the subject, the psychopathological manifestations represented in everyday life are raised by a cut, by some fact unmissable that condemns the subject to identify with the closest. Addiction arises as a morbid representation of the subject, forms inter subjective spaces and structures, in this sense, the clinic would work on the possibility of accounting in this psychic inter subjective process (identity) to understand that addiction is the ship through which the subject will become the trip (his life and history) without possible specific exit and that via speech would be the raft he would endure and the frenzy of addiction itself. The artificiality that addiction provides is a digital medium where phenomenological the addict feels the experience of linking with the other social, in some way, addiction provides what has been denied from the social, such distortion gives the subject immediate enjoyment but evokes an existential void, the absence of the effect of enjoyment is the anguish that leads the subject to perform acts of vandalism, destitution and / or suicide. It is crucial to raise the word of the addict from the clinic to sponsor a possible social rehabilitation, that is, the addict subject through a word clinic would be introduced to society as another, as a subject of progress. 


\section{Conclusion}

"In the cure we postulate as a goal that the patient, making his story thinkable, conduct his project or generate one. For this, it is necessary that he narcissistically invites his actuality, but also the future time, valuing his change, his alteration, since, a subject in becoming can only persist becoming another, accepting to discover himself different from what he was and from which he "should become" [9] difference that takes effect when the subject persists from addiction, but to make a difference you have to make the word possible, renouncing the enjoyment of the help caused by the addiction implies asserting the word of that which is denied with the addiction and worries, restoring the social bond via the word would justify an identity in order, within the order of knowledge, so desire becomes dynamic and flows in the body. To say "Lacan conceived a clinic that does not go back to the impossible; Moreover, it becomes the core of the analytical experience and makes it unpublished. Where that impossible is dressed as an obstacle, there it offers the way to go beyond the therapeutic. It is already indicated by the Freudian conception of sexuality as a substrate of the symptom, traumatic sexuality because it suffers from an essential disorder of the significant effect on the body, a libidinal body affected by the unconscious, modeled by a pulse circuit that creates itself as an object, drawing a vacuum and holding an absence that is nothing. Body of the written parletre of marks where signifiers and contingency are articulated, but also the subject's consent" [10]. The effects that are manifested in addiction have their eminence in language, they are essential for the clinical space to speak and precipitate the qualities for strong and healthy modes of activity in the subject who enters the clinical intervention. That is to say, the links by which the addict refuses to establish due to the determined identity problems make them realize the need to give space to the word within the clinic, which as a premise is to give it an accepted order within social practices. The work can be done from a certain methodology that makes the symptom (addiction) understood as a configurator of the subject but can be enhanced via the word.

\section{References}

1. Jauregui I (2002) A cultural perspective of addiction. Anthropology Gazette 18: 1-10.

2. WHO (1994) Glossary of alcohol and drug terms. World Health Organization, Geneva.

3. Pretel M, González B, Machado A, Fernandez O, Toledo Y (2014) Alcoholism and its impact: an approach from Health Psychology. Magazine 4: 261-270.

4. González J (2008) Psychoanalysis and Drug Addiction. Journal of Psychoanalysis, Psychotherapy and Mental Health 1: 1-21.

5. Government of Mexico (2019) Report on the Situation of Drug Consumption in Mexico and its Comprehensive Care.

6. Freud S (1991) Psychology of the masses. Mexico City: Editorial Alliance Government of Mexico. Report on the Situation of Drug Consumption in Mexico and its Comprehensive Care.

7. Ovejero A (2000) Addiction as a search for identity: a theoretical psychosocial basis for effective intervention. Psychosocial Intervention 9: 199215.

8. Lacan J (2009) Glossary of alcohol and drug terms. Geneva, Word Health Organization, Century Publishers.

9. Hornstein L (2014) Listening, Symbolization and Psychoanalytic Cure. Errancia Magazine, UNAM 9: 1-14.

10. Dicker S (2014) From the Failure in Knowledge to the Desire to Know. Errancia Magazine, UNAM 9: 1-4. 


\section{Hit}

Journal of Anesthesia \& Clinical Care

Journal of Addiction \& Addictive Disorders

Advances in Microbiology Research

Advances in Industrial Biotechnology

Journal of Agronomy \& Agricultural Science

Journal of AIDS Clinical Research \& STDs

Journal of Alcoholism, Drug Abuse \& Substance Dependence

Journal of Allergy Disorders \& Therapy

Journal of Alternative, Complementary \& Integrative Medicine

Journal of Alzheimer's \& Neurodegenerative Diseases

Journal of Angiology \& Vascular Surgery

Journal of Animal Research \& Veterinary Science

Archives of Zoological Studies

Archives of Urology

Journal of Atmospheric \& Earth-Sciences

Journal of Aquaculture \& Fisheries

Journal of Biotech Research \& Biochemistry

Journal of Brain \& Neuroscience Research

Journal of Cancer Biology \& Treatment

Journal of Cardiology: Study \& Research

Journal of Cell Biology \& Cell Metabolism

Journal of Clinical Dermatology \& Therapy

Journal of Clinical Immunology \& Immunotherapy

Journal of Clinical Studies \& Medical Case Reports

Journal of Community Medicine \& Public Health Care

Current Trends: Medical \& Biological Engineering

Journal of Cytology \& Tissue Biology

Journal of Dentistry: Oral Health \& Cosmesis

Journal of Diabetes \& Metabolic Disorders

Journal of Dairy Research \& Technology

Journal of Emergency Medicine Trauma \& Surgical Care

Journal of Environmental Science: Current Research

Journal of Food Science \& Nutrition

Journal of Forensic, Legal \& Investigative Sciences

Journal of Gastroenterology \& Hepatology Research

Journal of Gerontology \& Geriatric Medicine
Journal of Genetics \& Genomic Sciences

Journal of Hematology, Blood Transfusion \& Disorders

Journal of Human Endocrinology

Journal of Hospice \& Palliative Medical Care

Journal of Internal Medicine \& Primary Healthcare

Journal of Infectious \& Non Infectious Diseases

Journal of Light \& Laser: Current Trends

Journal of Modern Chemical Sciences

Journal of Medicine: Study \& Research

Journal of Nanotechnology: Nanomedicine \& Nanobiotechnology

Journal of Neonatology \& Clinical Pediatrics

Journal of Nephrology \& Renal Therapy

Journal of Non Invasive Vascular Investigation

Journal of Nuclear Medicine, Radiology \& Radiation Therapy

Journal of Obesity \& Weight Loss

Journal of Orthopedic Research \& Physiotherapy

Journal of Otolaryngology, Head \& Neck Surgery

Journal of Protein Research \& Bioinformatics

Journal of Pathology Clinical \& Medical Research

Journal of Pharmacology, Pharmaceutics \& Pharmacovigilance

Journal of Physical Medicine, Rehabilitation \& Disabilities

Journal of Plant Science: Current Research

Journal of Psychiatry, Depression \& Anxiety

Journal of Pulmonary Medicine \& Respiratory Research

Journal of Practical \& Professional Nursing

Journal of Reproductive Medicine, Gynaecology \& Obstetrics

Journal of Stem Cells Research, Development \& Therapy

Journal of Surgery: Current Trends \& Innovations

Journal of Toxicology: Current Research

Journal of Translational Science and Research

Trends in Anatomy \& Physiology

Journal of Vaccines Research \& Vaccination

Journal of Virology \& Antivirals

Archives of Surgery and Surgical Education

Sports Medicine and Injury Care Journal

International Journal of Case Reports and Therapeutic Studies

Submit Your Manuscript: http://www.heraldopenaccess.us/Online-Submission.php 